\title{
THE RELATIONSHIP BETWEEN CHRONIC FATIGUE SYNDROME, BURNOUT, JOB SATISFACTION, SOCIAL SUPPORT AND AGE AMONG ACADEMICS AT A TERTIARY INSTITUTION
}

\author{
NICOLEEN COETZEE, DAVID JACOBUS FRANCOIS MAREE, and BYRON NEL SMIT
}

University of Pretoria, Pretoria, South Africa

Department of Psychology

\begin{abstract}
Objectives: Over the last 20 years, tertiary institutions have been subjected to several changes. This has resulted in increased workloads for academics. Some academics have started to experience symptoms that are related to chronic fatigue syndrome and burnout. Researchers, however, cannot agree whether the 2 syndromes are two sides of the same coin or actually 2 separate constructs. This study that was conducted at a tertiary institution in South Africa therefore aimed to determine if these constructs accounted for the evidence of the same syndrome within an academic setting or if they were 2 separate, distinguishable constructs. However, since job satisfaction and social support play a role in the poor physical and psychological health experienced by individuals with chronic fatigue syndrome or burnout, it was decided to also include these 2 constructs into the investigation. Age was also incorporated because it had dissimilar relationships with burnout and chronic fatigue syndrome. Material and Methods: The participants completed the following questionnaires via an online survey: The Centers for Disease Control and Prevention Chronic Fatigue Syndrome Symptom Inventory, the Oldenburg Burnout Inventory, the Overall Job Satisfaction Scale and the Social Support Scale. The data was used for constructing a structural equation model. Results: Job satisfaction was found to be a strong predictor of burnout. The number of symptoms indicative of chronic fatigue syndrome reported by the participants proved to be a relatively strong significant predictor of burnout. Age did not yield any significant relationship with any of the constructs. Conclusions: The results indicated that chronic fatigue and burnout should be perceived as 2 distinguishable constructs in the academic context. It should be noted, however, that some overlap exists between them. Int J Occup Med Environ Health. 2019;32(1):75-85
\end{abstract}

Key words:

social support, job satisfaction, burnout, structural equation modeling, chronic fatigue syndrome, academic institutions

\section{INTRODUCTION}

According to Doyle and Hind [1], academic work was regarded as a profession with little stress up until the late 1990s. This, however, has changed over the last 20 years as tertiary institutions have been subjected to numerous changes [2]. Some of these changes have involved increased managerial control, increased competition with other tertiary institutions, an increase in the number of audits being conducted, as well as remodeling of day-today activities and operations to resemble corporate organizations [2]. In South Africa, these changes have resulted in the creation of a new organizational culture [3] where fewer staff members are expected to deal with an increase in student numbers and hence a higher teaching load [4,5], the introduction of Internet-based educa-

Received: September 30, 2017. Accepted: May 14, 2018.

Corresponding author: Nicoleen Coetzee, University of Pretoria, Department of Psychology, Lynnwood Road, Pretoria, 0002, South Africa (e-mail: nicoleen.coetzee@up.ac.za). 
tion [4], increased research output [5] and an increase in administrative responsibilities [3].

In addition to the changes to the organizational culture of universities, academics in South Africa are also faced with job insecurity. According to a survey by Bloomberg, South Africa has one of the highest unemployment rates [3]. With governments cutting their subsidies to universities, universities need to make harsh decisions with regard to expenditure and some have indicated that they even consider retrenchments [3]. It is against this background that Smit [3] has noted that more academics complain about symptoms related to either chronic fatigue syndrome or burnout.

Over the years, several definitions have been developed to define chronic fatigue syndrome [6-8]. The one currently most accepted by researchers is the definition used by the Centers for Disease Control and Prevention (CDC) [9]. The CDC definition contains the following aspects [9]:

- an individual has had severe chronic fatigue for $\geq 6$ consecutive months and it is not the result of on-going exertion or other medical conditions associated with fatigue;

- these conditions need to be ruled out by a medical doctor after several diagnostic tests are conducted;

- the fatigue significantly interferes with daily work and activities.

An individual suffering from chronic fatigue concurrently has $\geq 4$ of the following 8 symptoms:

1. post-exertion malaise that lasts for $>24 \mathrm{~h}$,

2. unrefreshing sleep,

3. significant impairment of short-term memory or concentration,

4. muscle pain,

5. pain in joints without swelling or redness,

6. headaches of a new type, pattern or severity,

7. tender lymph nodes in the neck or armpit,

8. sore throat that is frequent or recurring.
Burnout, on the other hand, is defined as "a syndrome of emotional exhaustion, depersonalization and reduced personal accomplishment" that often occurs among staff working with other individuals [10]. Academics are an excellent example of individuals facing high demands from other people and institutions. The main characteristics of burnout are:

- exhaustion that is a result of prolonged exposure to specific working conditions, and

- disengagement in terms of which an employee distances him/herself from work and other staff members, and develops negative attitudes towards work [11].

Although Hyland has suggested that chronic fatigue syndrome develops because of immunological challenges and lifestyle pressures associated with being an academic, some researchers still confuse it with burnout [3]. Leone et al.'s [7] findings contribute to this confusion because they have pointed out that chronic fatigue syndrome has at least 3 characteristics in common with burnout. These are:

- at the heart of both syndromes lies the issue of serious exhaustion or fatigue;

- people who suffer from these syndromes often share the same personality traits (active, hardworking, passionate and dedicated);

- both syndromes are related to work overload.

Burnout also mimics chronic fatigue syndrome in that it is associated with poor health issues such as headaches, fatigue, sleep disturbances and exhaustion [11,12]. Another common factor between academics suffering from chronic fatigue syndrome and burnout is that they struggle to be productive in creative ways $[3,13]$.

As a result of these contradictory findings, it is necessary to determine whether chronic fatigue and burnout experienced by academics are the same syndrome or if they are 2 separate, distinguishable constructs. Ismail et al. [11], however, noted that in any study involving burnout, job satisfaction and social support also need to be investigated 
because they are significant predictors of the occurrence of burnout and might explain why burnout is present. These constructs will hence be briefly explored in what follows.

\section{Job satisfaction}

According to Werther and Davis [14], job satisfaction may be defined as the amount of favorableness or unfavorableness with which an employee views his/her job. It hence refers to how positive/negative or happy/unhappy an individual is in his/her job [11,15]. Ahsan et al. [16] have found in their study that job satisfaction has an impact on the amount of burnout academics experience when trying to cope with the demands placed on them. These results were confirmed by Salehi and Gholtash [17] who noted a negative relationship between job satisfaction and burnout when studying the organizational citizenship behavior of a group of academics. A recent study conducted by Høigaard et al. [18] in Norway investigated the relationship between job satisfaction and burnout among teachers and, again, a strong negative correlation was observed between these two. Interestingly enough, Ogresta et al. [19] found an inverse correlation between the experience of job satisfaction and the psychological and physical manifestations of occupational stress when they conducted a study on mental health workers. This suggests that academics who view their jobs in a negative light will experience psychological and physical ailments as a result of their unhappiness.

\section{Social support}

Social support may be defined as an academic's belief that he/she is valued, loved and cared for by those in the institution and by others [11]. It thus involves the extent to which the academic perceives that he/she is empowered by helping relationships of varying strength and quality which include resources such as emotional assistance, appropriate aid inside and outside the workplace, and the necessary communication of information $[11,20]$.
Social support is especially important in the workplace because it may result in academics experiencing the work demands more positively [11,21]. It is furthermore interesting to note that studies conducted by Ozbay et al. [22], as well as by Umberson and Montez [23], have found that social support does not only impact psychological health, but physical health as well. As is the case with job satisfaction, poor social support apparently also plays a role in academics experiencing poor health and psychological issues.

\section{Age, chronic fatigue syndrome and burnout}

Given the notion that job satisfaction and social support might play a role in the experience of chronic fatigue syndrome and burnout, Smit [3] has noted that the 2 constructs have 1 other variable in common, namely age. However, findings related to the role of age in the experience of chronic fatigue syndrome and burnout are contradictory.

A study conducted by Jason et al. [24] in the U.S. has shown that older individuals are at a greater risk of suffering from chronic fatigue syndrome. The researchers cited the age of 40-49 as a high risk period for individuals working under stressful conditions. Gallagher et al. [25] supported these findings. They conducted a meta-analysis of data collected $>10$ years and found that chronic fatigue syndrome was more prevalent in older groups.

Younger age groups, on the other hand, appear to be at a greater risk of suffering from burnout [26]. Brewer and Shaphard [27], who also conducted a meta-analysis of the prevalence of burnout, discovered an inverse correlation between age and burnout. Younger employees were therefore much more likely to develop burnout.

Smit [3], however, disputed the findings because of the dated studies. He suggested that, in order to determine if chronic fatigue and burnout is the same syndrome or if they are 2 separate, distinguishable constructs, one needs to investigate the impact of age as well. 


\section{MATERIAL AND METHODS}

\section{Sampling frame and participants}

An academic institution was identified for the study and the necessary permission was obtained from the relevant faculty committees to conduct the research. Permission was also obtained from the Ethics Committee of the Faculty of $\mathrm{Hu}$ manities. The survey committee of the institution, however, decided not to give the researchers access to the email addresses of staff members, citing an issue of confidentiality because one of the researchers was a student. The researchers were, however, allowed to advertise the research on an internal news site that was circulated amongst the staff. The questionnaires were uploaded in electronic format to a website created specially for this particular research, and the URL of this website was provided on the internal news site. Informed consent and a guarantee of confidentiality formed part of the survey. In the end, 69 participants (of 1433 personnel members) visited the URL and uploaded their responses to the questionnaires. The majority $(75.36 \%)$ of the respondents were women aged 23-72 ( $\mathrm{M}=40.36$, $\mathrm{SD}=11.08$ ). The number of years of working at the institution ranged from a couple of months to as many as 38 years $(\mathrm{M}=8.74, \mathrm{SD}=9.1)$. Most of the participants were either lecturers $(20.29 \%)$ or senior lecturers $(26.09 \%)$.

\section{Measuring instruments}

The participants completed the following measures: the Centers for Disease Control and Prevention Chronic Fatigue Syndrome Symptom Inventory (CDC CFS Symptom Inventory) [28], the Oldenburg Burnout Inventory (OLBI) [29], the Overall Job Satisfaction Scale [30,31] and the Social Support Scale [32].

\section{Centers for Disease Control and Prevention} Chronic Fatigue Syndrome Symptom Inventory

The Centers for Disease Control and Prevention Chronic Fatigue Syndrome Symptom Inventory (CDC CFS Symptom Inventory) was used for measuring for the presence of chronic fatigue syndrome. It consists of 57 items that measure the presence, frequency and intensity of 19 fatigue-related symptoms, and 8 symptoms that define chronic fatigue syndrome. The latter are referred to as core symptoms. The tool also measures the incidence of diarrhea, fever, chills, sleep-related problems, nausea, stomach or abdominal pain, sinus or nasal problems, breathing deficiencies, light sensitivity and depression. These are known as the non-core symptoms [28]. The observed frequency of each symptom is rated on a 4-point Likert scale (1 - a little of the time, 2- some of the time, 3-most of the time, 4 -all of the time). The severity and intensity of the symptoms are measured on a 3-point Likert scale (1 - mild, 2 - moderate, 3 - severe). Wagner et al. [28] reported a Cronbach's $\alpha$ value of 0.88 for the measure. The Cronbach's $\alpha$ coefficient for the current sample is 0.94 .

\section{Oldenburg Burnout Inventory}

The Oldenburg Burnout Inventory (OLBI) was used for measuring burnout. It consists of 16 items containing 2 subscales, namely exhaustion and disengagement [29]. Each subscale consists of 8 items. Responses to the items are provided on a 4-point Likert scale ranging from 1 - completely disagree to 4 - completely agree. Test-retest of the measure yielded a Cronbach's $\alpha$ value of 0.85 [29]. The Cronbach's $\alpha$ coefficient for the current sample was 0.83 .

\section{Overall Job Satisfaction Scale}

The Overall Job Satisfaction Scale consists of 3 items to measure individuals' satisfaction with their current occupation [30]. Participants respond to the following items using a 7-point Likert scale (ranging from 1 - strongly disagree to 7 - strongly agree):

- "All in all, I am satisfied with my job;"

- "In general, I don't like my job;"

- "In general, I like working here."

Fields [31] conducted studies to investigate the reliability of the scale and reported Cronbach' $\alpha$ values of $0.67-0.95$. The Cronbach's $\alpha$ coefficient for the current sample was 0.82 . 


\section{Social Support Scale}

The Social Support Scale was developed by Caplan et al. [32]. It consists of 12 items measuring the support an individual receives at the workplace (from colleagues and managers) and in his/her personal environment (from friends and spouses). Participants respond using a 5-point Likert scale ranging from 0 - don't have any such person to 4 - very much. Cronbach's $\alpha$ values reported for the scale ranged 0.79-0.91 [33,34]. The Cronbach's $\alpha$ coefficient for the current sample was 0.83 .

\section{Data analyses}

Data was analyzed using a combination of descriptive statistics and structural equation modelling (SEM). SPSS Version 23 and IBM SPSS Amos were used for carrying out the analyses. Descriptive statistics were used for describing the data. Although some might argue that the present sample size is too small for SEM, Wolf et al. [35], as well as Sideridis et al. [36], have suggested that SEM could be conducted if the model could achieve goodness-of-fit. Furthermore, the reason for conducting the SEM related to the notion that it is a " $[. .$. good alternative to ordinary regressions in situations where there are multiple dependent and independent variables, and where there are unobserved, latent variables" [3,37].

\section{RESULTS}

The descriptive statistics obtained for the questionnaires are displayed in Table 1.

The variables used to carry out the SEM are depicted in Table 2.

The Goodness-of-Fit Statistics of the model are presented in Table 3.

The generated model is presented in Figure 1.

The model regression weights generated by the model are displayed in Table 4.

The unstandardized regression weights are used for determining the significance of the relationships between the dependent and independent variables. The standardized regression weights show the extent to which the dependent variables contribute to the independent variables.

The model shows that social support, to some extent, predicts both burnout and chronic fatigue syndrome, although the contribution is relatively small $(\gamma=-0.13$ and 0.11 respectively). Neither of these relationships, however, was found to be significant at $\mathrm{p} \leq 0.05$ ( $\mathrm{p}=0.22$ for social support and burnout, $\mathrm{p}=0.19$ for social support and fatigue).

Job satisfaction significantly predicts burnout $(\gamma=$ $-0.70, p \leq 0.001)$. Although job satisfaction appears to

Table 1. Descriptive statistics for the questionnaires used in the study [28-34]

\begin{tabular}{lccccc}
\hline \multicolumn{1}{c}{ Scale/Sub-scale } & $\mathrm{n}$ & $\mathrm{M}$ & $\mathrm{SD}$ & Min. & Max \\
\hline $\begin{array}{l}\text { Oldenburg Burnout Inventory (OLBI) } \\
\quad \text { exhaustion }\end{array}$ & 47 & 2.84 & 0.55 & 1.13 & 3.75 \\
$\quad$ disengagement & 47 & 2.47 & 0.47 & 1.38 & 3.38 \\
$\quad$ burnout overall & 47 & 2.66 & 0.44 & 1.44 & 3.31 \\
Centers for Disease Control and Prevention Chronic Fatigue Syndrome & & & & & \\
$\quad$ Symptom Inventory (CDC CFS Symptom Inventory) & & & & & \\
$\quad$ core symptoms & 50 & 5.30 & 2.27 & 0.00 & 9.00 \\
$\quad$ non-core symptoms & 50 & 4.08 & 2.41 & 0.00 & 9.00 \\
$\quad$ chronic fatigue overall & 50 & 9.38 & 4.41 & 0.00 & 18.00 \\
Social Support Scale & 47 & 2.53 & 0.65 & 1.08 & 3.75 \\
Overall Job Satisfaction Scale & 47 & 4.85 & 1.51 & 1.67 & 7.00 \\
\hline
\end{tabular}


Table 2. Variables used in the structural equation modelling (SEM) [28-34]

\begin{tabular}{ll}
\hline \multicolumn{1}{c}{ Dependent variables } & \multicolumn{1}{c}{ Independent variables } \\
\hline OLBI: Exhaustion & Job satisfaction \\
OLBI: Disengagement & Social Support: General at work \\
OLBI: Burnout Overall (Latent) & Social Support: Talk to \\
CDC CFS Symptom Inventory: Core symptoms & Social Support: Listen to \\
CDC CFS Symptom Inventory: Non-Core symptoms & Social Support: Total (Latent) \\
Chronic Fatigue Overall (Latent) & Number of symptoms \\
& Age \\
\hline
\end{tabular}

Abbreviations as in Table 1.

Table 3. Goodness-of-Fit Statistics of the structural equation model used in the study

\begin{tabular}{ccccccccc}
\hline Index & $\chi^{2}$ & $\mathrm{df}$ & $\mathrm{p}$ & RMSEA & PNFI & PRATIO & CFI & IFI \\
\hline Goodness-of-Fit & 70.42 & 29 & 0.00 & 0.16 & 0.45 & 0.53 & 0.90 & 0.91 \\
\hline
\end{tabular}

CFI - comparative fit index (good fit $>0.90)$; IFI - incremental fit index (good fit $>0.90)$; PNFI - parsimonious normed fit index (good fit $=$ approximately 0.50); PRATIO - parsimony ratio (good fit > 0.60); RMSEA - root mean square error of approximation (poor fit $>0.10$ ).

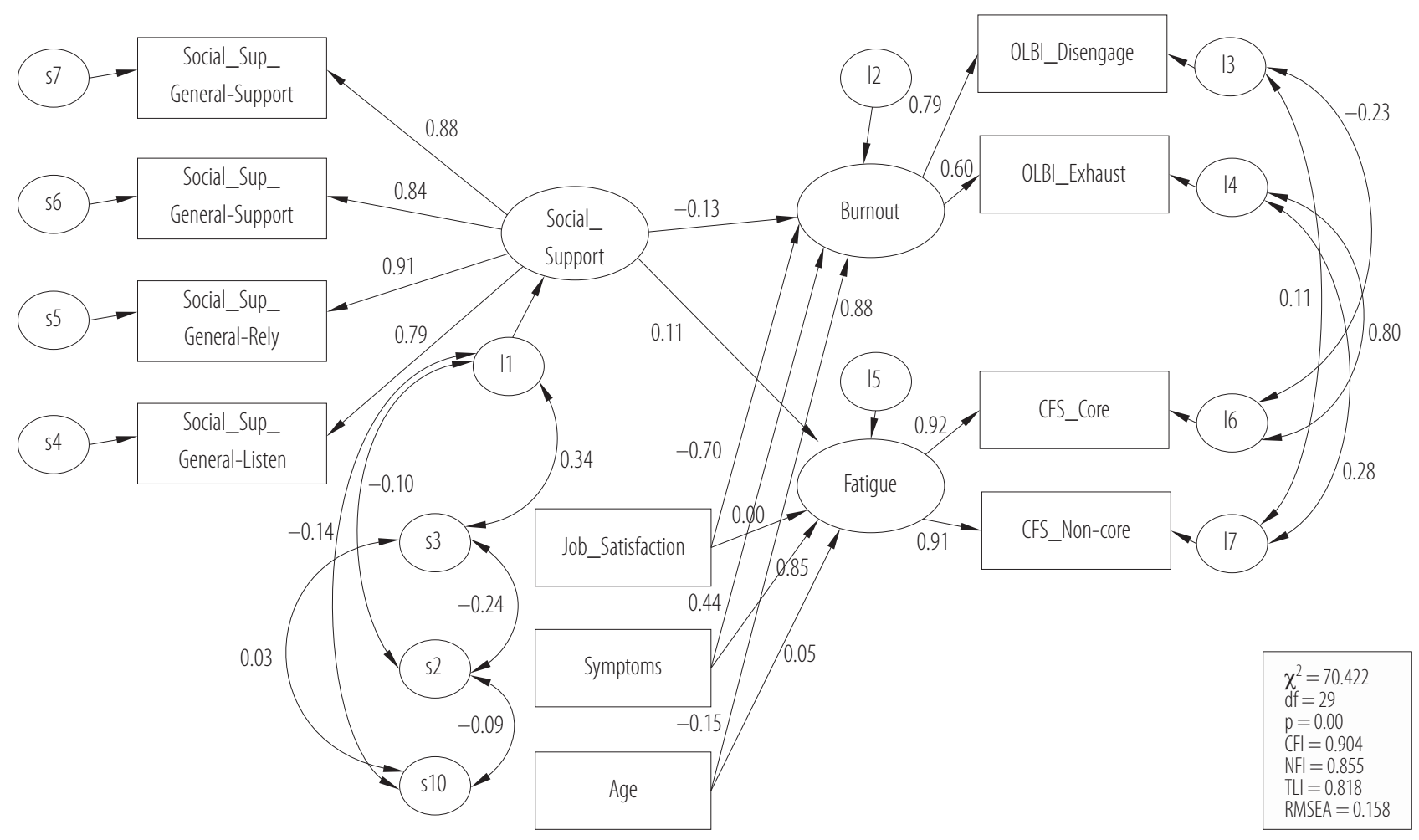

Goodness-of-Fit Statistics for this model in Table 3.

Figure 1. Structual equation modelling of the relationship between chronic fatigue syndrome, burnout, job satisfaction, social support and age 
Table 4. Model regression weights generated by the structural equation model used in the study

\begin{tabular}{lccccc}
\hline \multicolumn{1}{c}{ Variable } & \multicolumn{2}{c}{ Estimate } & & & \\
\cline { 2 - 4 } & raw & standardised & SE & CR & p \\
\hline Burnout $\leftarrow$ Job Satisfaction & -0.15 & -0.70 & 0.03 & -4.83 & $* * * *$ \\
Fatigue $\leftarrow$ Job Satisfaction & 0.00 & 0.00 & 0.77 & 0.00 & 1.00 \\
Burnout $\leftarrow$ Symptoms & 0.03 & 0.44 & 0.01 & 3.79 & $* * *$ \\
Fatigue $\leftarrow$ Symptoms & 2.76 & 0.85 & 0.30 & 9.09 & $* * *$ \\
Burnout $\leftarrow$ Social Support & -0.06 & -0.13 & 0.05 & -1.24 & 0.22 \\
Fatigue $\leftarrow$ Social Support & 2.27 & 0.11 & 1.72 & 1.32 & 0.19 \\
Burnout $\leftarrow$ Age & 0.00 & -0.15 & 0.00 & -1.51 & 0.13 \\
Fatigue $\leftarrow$ Age & 0.06 & 0.05 & 0.09 & 0.64 & 0.52 \\
Social Support Listen to $\leftarrow$ Social Support & 0.82 & 0.79 & 0.11 & 7.55 & $* * *$ \\
Social Support Rely Upon $\leftarrow$ Social Support & 1.00 & 0.91 & 0.10 & 9.67 & $* * *$ \\
Social Support Talk to $\leftarrow$ Social Support & 0.95 & 0.84 & 0.11 & 8.33 & $* * *$ \\
Social Support General $\leftarrow$ Social Support & 1.00 & 0.88 & & & \\
OLBI Disengagement $\leftarrow$ Burnout & 1.09 & 0.79 & 0.21 & 5.10 & $* * *$ \\
OLBI Exhaustion $\leftarrow$ Burnout & 1.00 & 0.60 & & & \\
CDC CFS Core $\leftarrow$ Fatigue & 1.42 & 0.92 & 0.13 & 11.03 & $* * *$ \\
CDC CFS Non-core $\leftarrow$ Fatigue & 1.00 & 0.91 & & & \\
\hline
\end{tabular}

Abbreviations as in Table 1.

*** Indicates significance at $\mathrm{p}<0.001$.

Table 5. Model covariances and correlations generated by the structural equation model

\begin{tabular}{|c|c|c|c|c|c|}
\hline \multirow{2}{*}{ Covariance } & \multicolumn{2}{|c|}{ Estimate } & \multirow{2}{*}{ SE } & \multirow{2}{*}{$\mathrm{CR}$} & \multirow{2}{*}{$\mathrm{p}$} \\
\hline & raw & standardised & & & \\
\hline Job Satisfaction $\leftrightarrow$ Social Support & 0.33 & 0.34 & 0.14 & 2.29 & 0.02 \\
\hline Symptoms $\leftrightarrow$ Social Support & -0.027 & -0.10 & 0.38 & -0.72 & 0.47 \\
\hline Symptoms $\leftrightarrow$ Job Satisfaction & -1.49 & -0.24 & 0.84 & -1.78 & 0.07 \\
\hline Job Satisfaction $\leftrightarrow$ Age & 0.52 & 0.03 & 2.15 & 0.24 & 0.81 \\
\hline Social Support $\leftrightarrow$ Age & -0.99 & -0.14 & 1.01 & -0.98 & 0.32 \\
\hline Symptoms $\leftrightarrow$ Age & -4.08 & -0.09 & 6.02 & -0.68 & 0.50 \\
\hline OLBI Disengagement $\leftrightarrow$ CFS Core Symptoms & -0.52 & -0.23 & 0.049 & -1.07 & 0.29 \\
\hline OLBI Disengagement $\leftrightarrow$ CFS Non-core Symptoms & 0.18 & 0.11 & 0.35 & 0.51 & 0.61 \\
\hline OLBI Exhaustion $\leftrightarrow$ CFS Core Symptoms & 2.82 & 0.80 & 0.84 & 3.37 & $* * *$ \\
\hline OLBI Exhaustion $\leftrightarrow$ CFS Non-core Symptoms & 0.73 & 0.28 & 0.54 & 1.34 & 0.18 \\
\hline Burnout $\leftrightarrow$ Fatigue & 0.25 & 0.69 & 0.24 & 1.07 & 0.28 \\
\hline
\end{tabular}

Abbreviations as in Table 1.

*** Indicates significance at $\mathrm{p}<0.001$. 
be a predictor of chronic fatigue syndrome, the correlation between these two was not found to be significant. The number of core and non-core symptoms which the participants reported was included in the model as an additional variable, primarily as an alternative measure of the relationship between physical symptoms associated with chronic fatigue and burnout. The number of symptoms experienced was found to predict both burnout and fatigue, with relatively high $\gamma$ values of 0.44 and 0.85 , respectively. Both of these relationships were found to be significant at $\mathrm{p} \leq 0.001$.

Age was found to be a weak, non-significant predictor of burnout $(\gamma=-0.15)$ and chronic fatigue syndrome $(\gamma=0.05)$.

The generated model also displays the covariance (r) between all variables which were used to create the model. Table 5 shows the initial model covariances which are used for determining whether the relationships between the variables are significant, as well as the extent to which they contribute to one another.

There is a relatively low level of covariance between social support and the number of symptoms, and the relationship is inversed. Similarly, the relationship between job satisfaction and the number of symptoms recorded is inversed, with a higher covariance than the previous relationship. The covariance between social support and job satisfaction is the greatest of all three. Of these 3 relationships, only the one between social support and job satisfaction was found to be significant at $\mathrm{p} \leq 0.05(\mathrm{p}=0.02)$. The relationship between job satisfaction and the number of symptoms leans towards significance at $p \leq 0.10$ $(\mathrm{p}=0.07)$.

Despite the relatively high covariance between burnout and fatigue (0.69), the analysis did not find the relationship to be significant $(\mathrm{p}=0.28)$.

Focusing on the relationships between the different sub-components of burnout (exhaustion and disengagement) and chronic fatigue syndrome (core and non-core symptoms) provides an additional interpretation of the relationship between the 2 syndromes. There appears to be a high $r$ for exhaustion and core symptoms (0.8) which was found to be significant at $p \leq 0.01$. Disengagement and core symptoms, however, appear to have an inverse relationship which was not found to be significant.

\section{DISCUSSION}

The model generated by SEM has shown that social support, job satisfaction and the number of symptoms recorded by participants all contribute to burnout and chronic fatigue syndrome, although not all of these relationships are significant. Job satisfaction has been found to be a strong predictor of burnout. This confirms the findings of previous research that has noted a strong relationship between job satisfaction and burnout [11,16-18]. This strong relationship might indicate a strong conceptual link between the 2 constructs [7].

Social support was found to be a generally weak predictor of burnout and chronic fatigue syndrome, and neither of the relationships was found to be significant. This is unusual considering that increased social support has been considered to promote physical and psychological health $[22,23]$. The results furthermore contradict a number of findings that have indicated a significant inverse relationship between burnout and social support [38-40]. A South African study, however, found that despite being significant, social support was a relatively weaker predictor of burnout when compared with job satisfaction [11]. As such, the non-significant relationship found in this study could probably be explained by the small sample size, and while the model which was generated does demonstrate that social support contributed to burnout and chronic fatigue syndrome, the amount of contribution was relatively small.

The number of symptoms indicative of chronic fatigue syndrome reported by participants proved to be a rela- 
tively strong significant predictor of burnout. This finding suggests a strong relationship between fatigue and burnout among the academics that participated in the study. These results confirm the findings of Ismail et al. [11], Leone et al. [7], and Spickard et al. [12], who have noted that both chronic fatigue syndrome and burnout have the characteristic of fatigue in common.

Although research [24-27] has suggested a relationship between age, chronic fatigue syndrome and burnout, this study could not confirm these findings. Instead, it confirmed the findings of Harry and Coetzee [41] who could not find a significant relationship between burnout and age. In spite of the fact that Brewer and Shapard [27] found a significant relationship between age and burnout, they could not find any such relationship when correlating burnout, chronic fatigue and age with one another.

In light of the findings, one can conclude that chronic fatigue syndrome and burnout experienced by academics are 2 separate and distinguishable constructs. However, the constructs overlap with regard to some characteristics displayed by both of them.

\section{Limitations of the study}

The biggest limitation of this study was the small sample size. Although the Goodness-of-Fit Index indicated that SEM could be conducted, the small number of significant predicators and correlations might be attributed to the small sample size used in this study. The current findings should hence be interpreted with caution.

Another limitation of the study is the cross-sectional nature of the study. Burnout and chronic fatigue syndrome develop over time, and a longitudinal study might have yielded different results when studying these constructs over a period of time.

Several studies have investigated the relationship between burnout, job satisfaction and social support. Future research could be simplified by merely focusing on the relationship between burnout and chronic fatigue syndrome.
The last limitation had to do with the fact that only 1 tertiary institution was used in the study. Although a higher number of participants was expected to react to the survey, one should remember that one limitation of survey research is that it normally has a low response rate. It is thus suggested that future research studies should incorporate more tertiary institutions.

\section{CONCLUSIONS}

Although the model generated through SEM did not provide concrete evidence of significant correlations between chronic fatigue syndrome, burnout, job satisfaction, social support and age, it alluded to certain relationships existing between the constructs. It is also important to note that a significant relationship was established between physical symptoms and burnout. It is hence concluded that, although chronic fatigue and burnout should be perceived as 2 distinguishable constructs in the academic context, some overlap exists between them. Since academics in South Africa are working under more stressful conditions, it is recommend that further research be conducted on the issue, especially since both burnout and chronic fatigue syndrome are known to lead to high absenteeism, low productivity and a decrease in research output.

\section{REFERENCES}

1. Doyle C, Hind P. Occupational stress, burnout and job status in female academics. Gend Work Organ. 1998;5(2):67-82, https://doi.org/10.1111/1468-0432.00047.

2. Jones S, Lefoe G, Harvey M, Ryland K. Distributed leadership: A collaborative framework for academics, executives and professionals in higher education. J High Educ Pol Manag. 2012;34(1):67-78, https://doi.org/10.1080/1360080X.2012. 642334 .

3. Smit BN. The relationship between burnout and chronic fatigue syndrome among academics at a tertiary institution [unpublished masters dissertation]. Pretoria: University of Pretoria; 2015. 
4. Coetzee SE, Rothmann S. An adapted model of burnout for employees at a higher education institution in South Africa. SA J Ind Psychol. 2007;30(3):29-40.

5. Houston D, Meyer LH, Paewai S. Academic staff workloads and job satisfaction: Expectation and values in academe. J High Educ Pol Manag. 2006;28(1):17-30, https://doi. org/10.1080/13600800500283734.

6. Holmes GP, Kaplan JE, Gantz NM, Komaroff AL, Schonberger LB, Straus SE. Chronic fatigue syndrome: A working case definition. Ann Intern Med. 1988;108(3):387-9, https:// doi.org/10.7326/0003-4819-108-3-387.

7. Leone SS, Wessely S, Huibers M, Knottnerus JA, Kane IJ. Two sides of the same coin? On the history and phenomenology of chronic fatigue and burnout. Psychol Health. 2011; 26(4):449-64, https://doi.org/10.1080/08870440903494191.

8. Manu P. The psychopathology of functional somatic syndromes: Neurobiology and illness behaviour in chronic fatigue syndrome, fibromyalgia, Gulf War illness, irritable bowel and premenstrual dysphoria. New York: Haworth Medical Press; 2004.

9. Centers for Disease Control and Prevention [Internet]. The Centers; 2012 [cited 2014 May 17]. Symptoms of ME/CFS. Available from: https://www.cdc.gov/me-cfs/symptoms-diagnosis/symptoms.html .

10. Maslach C. Burnout: The cost of caring. Cambridge: Malor Books; 2003.

11. Ismail HAK, Coetzee N, du Toit P, Rudolph EC, Joubert Y. Towards gaining a competitive advantage: The relationship between burnout, job satisfaction, social support and mindfulness. J Contemp Manag. 2013;10:448-64.

12. Spickard A, Gabbe S, Christensen JF. Mid-career burnout in generalist and specialist physicians. JAMA. 2002;288(2): 1447-50, https://doi.org/10.1001/jama.288.12.1447.

13. Kara D, Uysal M, Sirgy MJ, Lee G. The effects of leadership style on employee well-being in hospitality. Int J Hosp Manag. 2013;34:9-18, https://doi.org/10.1016/j.ijhm.2013.02.001.

14. Werther WB, Davis K. Human resources and personnel management. 5th ed. London: McGraw-Hill; 1999.
15. Salanova M, Del Libanno M, Llorens S, Schaufeli WB. Engaged, workaholic, burned-out or just 9-to-5? Toward a typology of employee well-being. Stress Health. 2014;30(1):7181, https://doi.org/10.1002/smi.2499.

16. Ahsan N, Abdullah Z, Fie DYG, Alam SS. A study of job stress on job satisfaction among university staff in Malaysia: An empirical study. Eur J Soc Sci. 2009;8(1):121-31.

17. Salehi M, Gholtash A. The relationship between job satisfaction, job burnout and organization commitment with the organizational citizenship behaviour among members of faculty in the Islamic Azad University - First district branches, in order to provide the appropriate model. Procedia Soc Behav Sci. 2011;15:306-10, https://doi.org/10.1016/j.sbspro.2011.03.091.

18. Høigaard R, Giske R, Sunsdsli K. Newly qualified teachers' work engagement and teacher efficacy influences on job satisfaction, burnout, and the intention to quit. Eur J Teach Educ. 2012;35(3):347-57, https://doi.org/10.1080/02619768. 2011.633993.

19. Ogresta J, Rusac S, Zorec L. Relation between burnout syndrome and job satisfaction among mental health workers. Croat Med J. 2008;49(3):364-74, https://doi.org/10.3325/ cmj.2008.3.364.

20. Viswesvaran C, Sanchez JI, Fisher J. The role of social support in the process of work stress: A meta-analysis. J Vocat Behav. 1999;54(2):314-34, https://doi.org/10.1006/jvbe. 1998.1661.

21. Kossek EE, Pichler S, Bodner T, Hammer LB. Workplace social support and work-family conflict: A meta-analysis clarifying the influence on general and work-family-specific supervisor and organizational support. Pers Psychol. 2011;64(2): 289-313, https://doi.org/10.1111/j.1744-6570.2011.01211.x.

22. Ozbay F, Johnson DC, Southwick S. Social support and resilience to stress. Psychiatry (Edgmont). 2007;4(5):35-40.

23. Umberson D, Montez JK. Social relationships and health: A flashpoint for health policy. J Health Soc Behav 2010;51 (Suppl):S54-66, https://doi.org/10.1177/0022146510383501.

24. Jason LA, Richman JA, Rademaker AW, Jordan KM, Plioplys AV, Taylor RR, et al. A community-based study of chro- 
nic fatigue syndrome. Arch Intern Med. 1999;159(18):212937, https://doi.org/10.1001/archinte.159.18.2129.

25. Gallagher AM, Thomas JM, Hamilton WT, White PD. Incidence of fatigue symptoms and diagnoses presenting in UK primary care from 1990 to 2001. J R Soc Med. 2004;97 (12):571-75, https://doi.org/10.1177/014107680409701204.

26. Maslach C, Schaufeli WB, Leiter MP. Job burnout. Annu Rev Psychol. 2001;52:397-422, https://doi.org/10.1146/annu rev.psych.52.1.397.

27. Brewer EW, Shapard L. Employee burnout. A meta-analysis of the relationship between age or years of experience. Hum Resour Dev Rev. 2004;3(2):102-23, https://doi. org/10.1177/1534484304263335.

28. Wagner D, Nisenbaum R, Heim C, Jones JF, Unger ER, Reeves WC. Psychometric properties of the CDC Symptom Inventory for assessment of Chronic Fatigue Syndrome. Popul Health Metr. 2005;3:8, https://doi.org/10.1186/1478-7954-3-8.

29. Demerouti E, Bakker AB. The Oldenburg Inventory: A good alternative to measure burnout and engagement. In: Halbesleben JRB, editor. Handbook of stress and burnout in health care. Hauppauge: Nova Science; 2008. p. 65-78.

30. Cammann C, Fichman M, Jenkins D, Klesh J. Assessing the attitudes and perceptions of organizational members. In: Seashore S, Lawler E, Mirvis P, Cammann C, editors. Assessing organizational change: A guide to methods, measures and practices. New York: John Wiley; 1983. p. 71-138.

31. Fields D. Taking the measure of work: A guide to validated scales for organizational research and diagnosis. London: Sage Publications; 2002, https://doi.org/10.4135/9781452231143.

32. Caplan R, Cobb S, French J, Van Harrison R, Pinneau S. Job demands and worker health. Ann Arbor: University of Michigan, Institute for Social Research; 1980.
33. Lee R, Ashforth B. A further examination of managerial burnout: Toward an integrated model. J Organ Behav. 1993;14:3-20, https://doi.org/10.1002/job.4030140103.

34. Repetti RL, Cosmas KA. The quality of the social environment at work and job satisfaction. J Appl Soc Psychol. 1991;21(10): 840-54, https://doi.org/10.1111/j.1559-1816.1991.tb00446.x.

35. Wolf EJ, Harrington KM, Clark SL, Miller MW. Sample size requirements for structural equation models. An evaluation of power, bias and solution propriety. Educ Psychol Meas. 2013; 73(6):913-34, https://doi.org/10.1177/0013164413495237.

36. Sideridis G, Simos P, Papanicolaou A, Fletcher J. Using structural equation modeling to assess functional connectivity in the brain power and sample size considerations. Educ Psychol Meas. 2014;74(5):733-58, https://doi. org/10.1177/0013164414525397.

37. Savelei V, Bentler PM. Structural equation modelling. In: Grover R, Vriens M, editors. The handbook of marketing research: uses, misuses, and future advances. Thousand Oaks: SAGE; 2006. p. 330-64.

38. Gustaffson G, Eriksson S, Strandberg G, Norberg A. Burnout and perceptions of conscience among health care personnel: A pilot study. Nurs Ethics. 2010;17(1):23-38, https:// doi.org/10.1177/0969733009351950.

39. Naugle KE. Perceptions of wellness and burnout among certified athletic trainers: Contributions of the wellness domains. Diss Abstr Int A. 2010;70(7-A):2404.

40. Tsai F, Chan C. Occupational stress and burnout of judges and procurators. Int Arch Occup Environ Health. 2010;83(2): 133-42, https://doi.org/10.1007/s00420-009-0454-1.

41. Harry N, Coetzee M. Sense of coherence, affective wellbeing and burnout in a South African higher education institution call centre. SA J Labour Rel. 2011;25(2):26-46.

This work is available in Open Access model and licensed under a Creative Commons Attribution-NonCommercial 3.0 Poland License - http://creativecommons.org/ licenses/by-nc/3.0/pl/deed.en. 